\title{
Individual-Level Determinants of the Public Acceptance of Policy Measures to Improve Urban Air Quality: The Case of the Barcelona Low Emission Zone
}

\author{
Christian Oltra $^{1, *(\mathbb{D})}$, Roser Sala ${ }^{1}$, Sergi López-Asensio ${ }^{1} \mathbb{D}$, Silvia Germán ${ }^{1}$ and Àlex Boso ${ }^{2}$ (D) \\ 1 Deptartment of Environment, Socio-Technical Research, CIEMAT, 28040 Madrid, Spain; \\ roser.sala@ciemat.es (R.S.); sergi.lopez@ciemat.es (S.L.-A.); silvia.german@ciemat.es (S.G.) \\ 2 Núcleo en Ciencias Sociales y Humanidades \& Butamallin Research Center for Global Change, \\ Universidad de la Frontera, Temuco 4780000, Chile; alex.boso@ufrontera.cl \\ * Correspondence: christian.oltra@ciemat.es; Tel.: +34-935868789
}

Citation: Oltra, C.; Sala, R.;

López-Asensio, S.; Germán, S.; Boso, À. Individual-Level Determinants of the Public Acceptance of Policy Measures to Improve Urban Air Quality: The Case of the Barcelona Low Emission Zone. Sustainability 2021, 13, 1168. https://doi.org/ $10.3390 /$ su13031168

Academic Editor: Massimo Aria Received: 27 October 2020

Accepted: 18 January 2021

Published: 22 January 2021

Publisher's Note: MDPI stays neutral with regard to jurisdictional claims in published maps and institutional affiliations.

\begin{abstract}
A variety of policy instruments that impose restrictions on traffic are being put in place across European cities to improve urban air quality. These measures include various schemes such as congestion charges, low emission zones (LEZs) and other traffic calming measures. In this paper, we are interested in the public acceptance of LEZs. Recent studies show high levels of public support for LEZs across Europe. However, specific research on public attitudes towards LEZs is limited. We conducted a self-administered survey (online) among residents in Barcelona, Spain. Based on a previous analytical model, bivariate and path analysis modelling was used to examine the association between key independent variables and acceptance. The results showed that most surveyed residents had a positive attitude towards implementing the LEZ, perceiving this policy instrument as a fair and effective measure to reduce air pollution. Perceived process legitimacy, perceived global impacts and affect had a significant direct effect on acceptance. Prior attitudes and personal orientations and, to a lesser extent, personal characteristics, were indirectly associated with levels of acceptance.
\end{abstract}

Keywords: car use reduction; air quality; survey; attitudes

\section{Introduction}

Levels of air pollution are a significant problem in all urban areas of the world. In Europe, despite significant progress, poor air quality continues to cause serious health problems. To improve air quality levels in European cities, the European Commission adopted a Clean Air Policy Package in 2013. In 2018, the EC adopted the slogan "A Europe that protects: Clean air for all" [1] and provided national, regional and local actors with practical help to improve air quality in Europe. As air quality becomes an increasingly political issue and cities are forced to improve air quality, a variety of policy instruments that impose restrictions on traffic in demarcated areas are being put in place across Europe. These measures include various schemes such as urban road tolls, low emission zones (LEZs) and other traffic calming measures.

Low Emission Zones (LEZ) are areas within cities with restrictions on the operation of more polluting vehicles. Typically, only vehicles that meet specified pollution standards can enter LEZs. Swedish cities first introduced LEZs in the 1990s. There are currently more than 260 low emission zones in the EU Member States, among which 250 are concerned with passenger cars [2]. In countries such as Germany, the Netherlands and Italy, many cities have set up LEZs, and such zones have strong national support [3]. Barcelona, Madrid and Lisbon have recently implemented new LEZs. According to Holman, C., Harrison, R., and Querol [4], evidence on the efficacy of LEZs to improve urban air quality is mixed: there is some evidence from ambient measurements that LEZs in Germany, which also restrict heavy-duty vehicles (HDVs), have reduced long-term average PM10 and $\mathrm{NO}_{2}$ 
concentrations by a few percent. Elsewhere, where restrictions are limited to HDVs, the picture is much less clear.

In this paper, we are interested in the public acceptance of LEZs, that is, citizens' attitudes towards the LEZ or, more specifically, the favourable or unfavourable public reception of the measure after it was implemented. The acceptance by the local population of the policy instruments to control the flow of vehicles and reduce air pollution in urban areas is usually considered one of the main obstacles to the introduction of these measures [5-7]. Social research shows that certain coercive measures that may be necessary because of their effectiveness in reducing traffic flow and air pollution are difficult to implement because of the potential public opposition and the political difficulty of putting them into practice $[8,9]$. As a result, policymakers may adopt policies that are preferred by the majority of citizens but do not solve the problem effectively or efficiently $[10,11]$. The absence of public acceptance of a policy instrument can have other practical consequences, such as reducing the effectiveness of the measure [12] or forcing changes in the measures once implemented [13]. Understanding residents' perceptions, attitudes and satisfaction with LEZs can also help engagement and communications with residents.

The public acceptance of policy instruments to improve urban air quality generally varies across socio-political contexts. The same measure can generate a positive reaction in one city and be rejected in another, as shown by the different public reactions to the congestion tax in Edinburgh and Stockholm [14]. The levels of acceptance of a specific policy instrument can vary even among cities within the same country [15]. Attitudes also vary among individuals, as they are influenced by a number of diverse factors, including individuals' characteristics, motivations and prior attitudes, perceptions of the policy instrument itself and the political institutions responsible for its implementation [16-20].

Although specific research on attitudes towards LEZs is limited (for recent research on various policy instruments see, e.g., [21]), studies show high levels of public support for LEZs across Europe. For instance, a cross-national survey conducted in 2018 [2] showed that more than two thirds $(67 \%)$ of residents in the nine surveyed countries said they "somewhat" or "strongly support" measures that restrict access to city centres to cars with high emissions. The support for low emission zones was the highest in Hungary (77\%), Italy (74\%) and Great Britain (73\%) and lower in Belgium (60\%), France (60\%) and Germany $(57 \%)$. There is very limited published research on the determinants of public attitudes and acceptance of LEZs.

This paper aims to examine the individual level determinants of public acceptance of an LEZ. Based on a questionnaire survey among residents in Barcelona, our study expands upon previous research on the public acceptance of urban transport policy measures to examine the following research questions:

RQ1. What is the level of public acceptance of the LEZ?

RQ2. What are the individual level variables associated with acceptance?

RQ3. What is the relative contribution of personal characteristics, problem perception, prior attitudes and perceptions of the policy instrument and the political institutions responsible for its implementation on acceptance?

\subsection{The Barcelona Low Emission Zone}

In order to improve air quality levels in Barcelona, the Barcelona Low Emission Zone came into force in January 2020 (Figure 1). The Barcelona LEZ is a protected area of over ninety-five square kilometres where vehicles without a specific environmental label cannot travel, so the entry of the most polluting vehicles is restricted: petrol cars registered before the Euro 3 standard (before 2000); diesel cars registered before the Euro 4 standard (before 2005 or 2006); motorcycles registered prior to Euro 2 (before 2003). From 2021, vans, lorries and buses without an environmental label will also be affected. It is estimated that around 50,000 vehicles will no longer enter the area. 


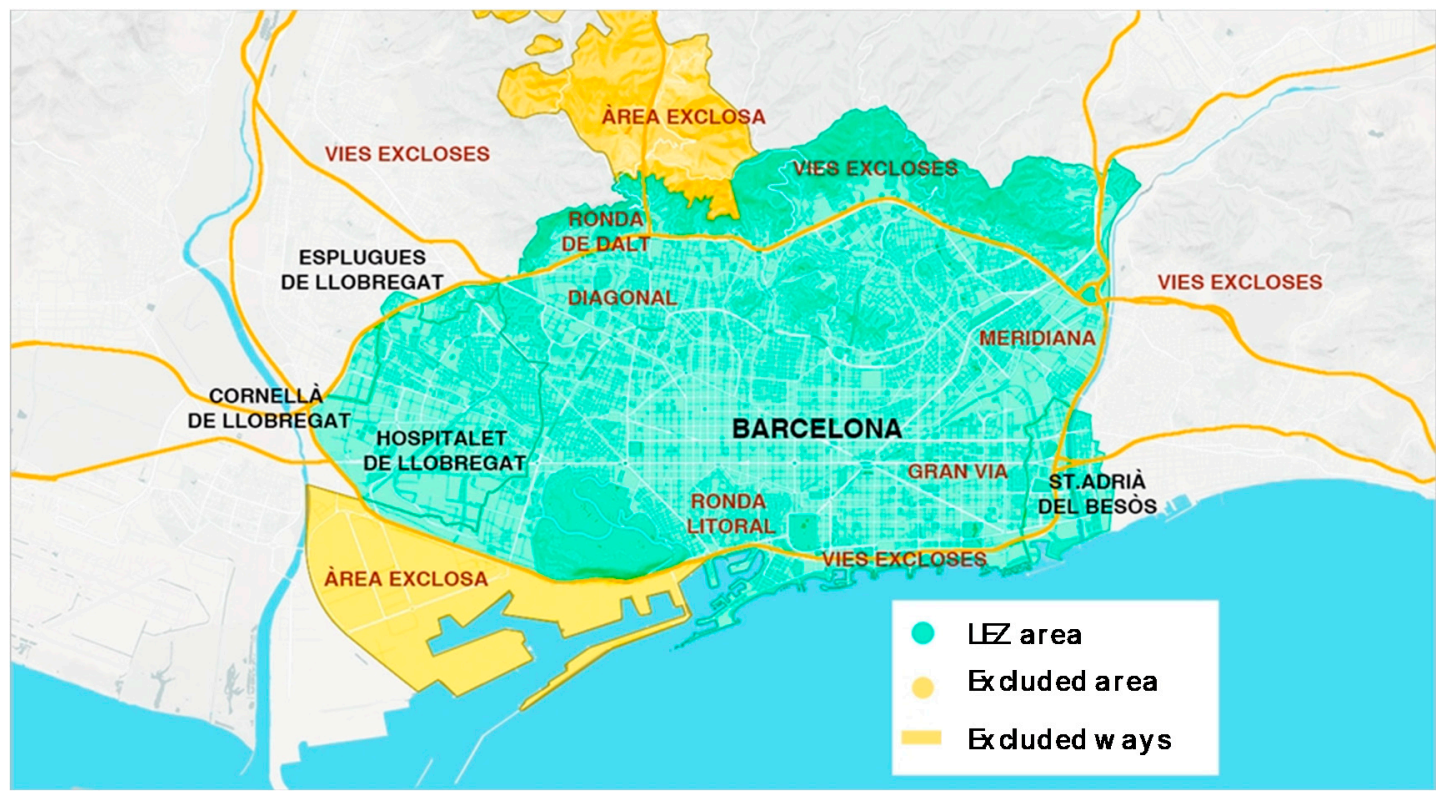

Figure 1. Map of the low emission zone (LEZ) in Barcelona (Source: Barcelona City Council).

The Low Emission Zone will be permanent, from Monday to Friday, on working days from $7 \mathrm{am}$ to $8 \mathrm{pm}$. The scheme is accompanied by other actions to improve sustainable mobility, such as reinforcing public transport. The Barcelona City Council foresee that by limiting the circulation of the most polluting vehicles, $\mathrm{NO}_{2}$ emissions will be reduced by $15 \%$.

In 2019, a participative process was launched to promote debate and exchange between citizens and local policymakers regarding the permanent LEZ implementation. The aim was to inform and to collect residents' opinions and suggestions. Stakeholder representatives from a wide range of the city entities were involved in several meetings, and a webpage to collect direct feedback from citizens was developed. They found strong support for the implementation of the LEZ. Indeed, citizens requested more restrictive measures to achieve short-term results, such as to enlarge the fleet of affected vehicles or to extend the application schedule. Some concerns were raised about the need to have adequate infrastructure to adapt the vehicles, and other complementary measures (improve public transport, park and ride).

\subsection{Related Research and Analytical Framework}

Several studies during the past twenty years have investigated the public acceptance of policy measures to reduce traffic congestion and urban air pollution. This research, primarily consisting of survey studies on public attitudes towards road pricing schemes, has described public acceptance of these policy measures and investigated their individual-level and contextual determinants. In this section, we review some of these studies following a categorization of the factors influencing the acceptance of environmental, climate and transport policies $[19,22,23]$, as suggested in Figure 2.

The first set of relevant individual-level variables influencing the acceptance of congestion charge schemes includes sociodemographic variables (gender, age, education level or income), political ideology, car ownership or the dependence on the use of a car. Several studies have observed, for instance, that women, on average, report lower levels of support to these measures than men do $[6,24,25]$. Education, socioeconomic status and political ideology [26] have also been found to influence acceptance. Börjesson et al. [24], for instance, reported a significant effect of education and income on acceptance, those with the highest educational level and highest income being the ones who reported the highest level of support for a congestion charge. Basbas et al. [25] studied public attitudes towards a low-emission zone in Volos, Greece, and found lower levels of support among low income and young people. Schade and Schlag [7] found that of the different sociodemographic 
variables analysed, only socioeconomic status was weakly associated with acceptance of congestion charges in four European cities (Athens, Como, Dresden, and Oslo).

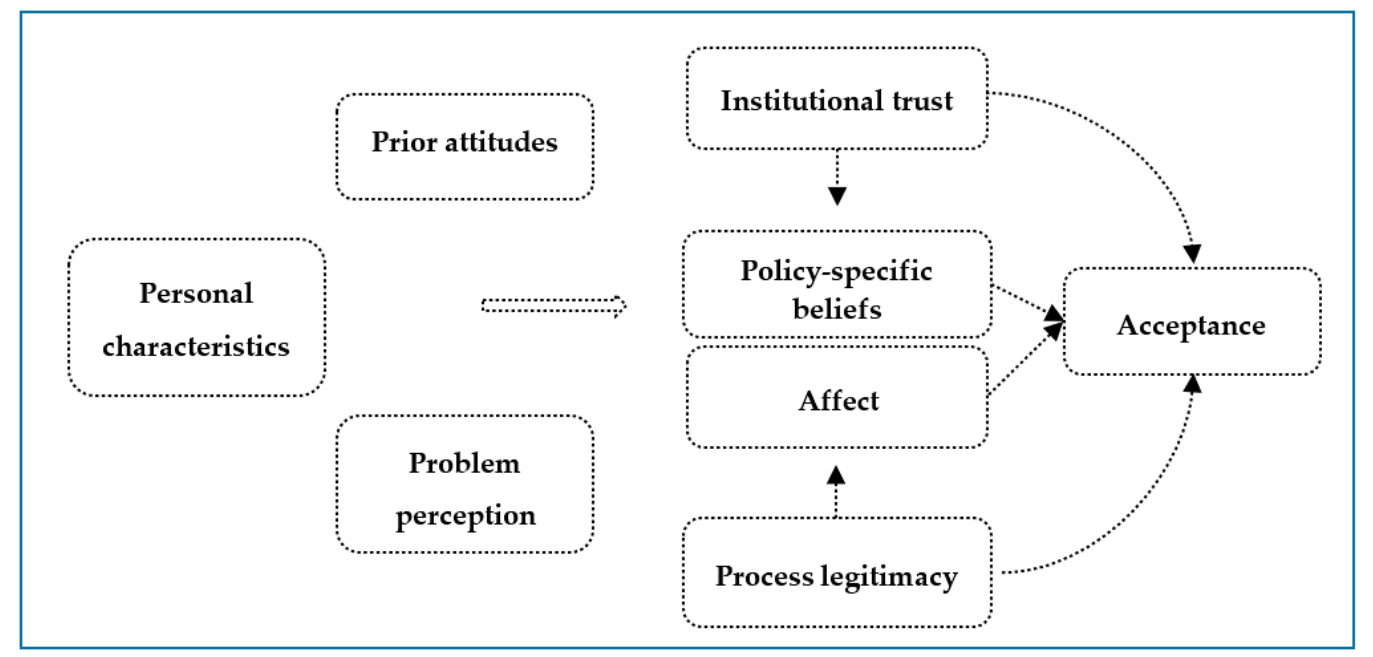

Figure 2. Suggested explanations for policy acceptance.

The effect of sociodemographics on acceptance often disappears when variables such as car dependence or attitudes towards the environment are controlled [6]. Regarding car ownership, Allen et al. [5], for instance, in the context of the referendum on the introduction of a congestion charge in Edinburgh, observed a correlation between car ownership and rejection of the measure. Similar results were found by Eliasson and Jonsson [6]. Rienstra et al. [27] point out that car drivers are more likely to be opposed to road pricing than non-car driving respondents, because the former group is more likely to be affected by this measure, whereas the latter may foresee benefits from the tax revenues raised.

Beyond sociodemographics, problem perception or problem awareness (traffic or environment-related) is also a relevant factor for policy acceptance. For instance, in a study in the Netherlands, Steg and Vlek [28] showed that the perception of traffic-related problems was a necessary precondition for regarding problem-solving measures as important. Other studies have also examined the relationship between problem perception and acceptance $[12,17,27]$. As suggested by Eriksson et al. [15], "if people are aware of transportrelated problems, they are more likely to think that road pricing schemes will change these problems, which in turn influences attitudes toward the road pricing schemes". A relevant distinction is made in the literature between traffic-related problem perception (such as congestion) and environment-related problem perception (e.g., air pollution, noise). For instance, a study in four European cities by Schade and Schlag [7] including exclusively motorists, showed that individuals who perceive traffic congestion as a non-serious problem rejected the congestion rate to a greater extent than individuals who fundamentally perceived air pollution as a serious problem.

Another set of significant individual-level determinants of acceptance consists of prior values, orientations, norms and attitudes. Given that the attitude towards a policy instrument is usually based on a limited experience of the policy itself, it tends to be less stable and, therefore, more influenced by associations with other attitudinal aspects such as individuals' environmental attitudes, attitudes towards taxes or personal norms [6]. A study by Eliasson and Jonsson [6], based on a survey with residents in the city of Stockholm, showed that attitudes towards the environment were strongly correlated with support for a proposed congestion rate. Similar results were found by Eriksson et al. [17] in a study of public acceptance of various traffic management measures in Sweden. A proenvironmental orientation was associated with the perception of the seriousness of the problem of urban pollution, the perception that the measure is effective and fair and, consequently, its acceptability. The study by Eriksson et al. [17] also showed a significant 
relationship between personal norms to reduce the negative environmental effects of car use and the acceptance of various policy instruments to reduce the use of cars. More recently, Nilsson et al. [20], in a three-wave survey panel study of attitudes and beliefs concerning a congestion tax in Gothenburg, Sweden, found that value expressive beliefs, such as the perception of impacts on personal freedom, were the most strongly related beliefs both for explaining attitudes and the change in attitudes after the implementation of the congestion tax.

Beyond sociodemographics, problem perception and prior orientations, perceptions and beliefs about the characteristics and potential impacts of the policy measure itself together with the personal feelings towards the policy are, probably, the main factors determining acceptance of a policy instrument $[7,17,19,27,29]$. Outcome expectancy, that is, the perception of benefits and costs associated with the instrument, is an attitudinal factor strongly associated with acceptance [6,27]. Eliasson and Jonsson [6] distinguish between the perception of the personal impacts of the instrument, related to the daily life of the individual, such as the impacts on personal freedom, cost, ease of transportation or security, and the perception of the systemic or social impacts, that is, on the whole of society, such as improving environmental quality or improving traffic. In a survey study on acceptance and attitudes towards a congestion rate in Stockholm, Eliasson and Jonsson [6] concluded that the perception of both types of impacts was associated with acceptability. Nevertheless, the literature has at least identified three other beliefs about a policy instrument influencing acceptance: perceived effectiveness, perceived impacts on freedom and perceived fairness $[19,29,30]$. The perceived effectiveness of the measure, that is, the degree to which the instrument is perceived to reduce air pollution or to improve traffic flow in the city, is considered one of the main determinants of attitude $[6,17]$. With perceived fairness, perceived effectiveness was found to predict the public acceptability of different transport policy measures in a study conducted in Sweden [17].

Finally, another set of relevant personal factors underlying the acceptance of a policy instrument are institutional trust and perceived process legitimacy [19]. Trust in the political institutions responsible for implementing a policy measure is a significant factor shaping attitudes in complex and contested issues. Moreover, although in some contexts, individuals' trust can be an expression of a more general attitude toward a particular policy, as people often base trust judgements on more general evaluative judgments [31], political trust is considered an essential factor explaining public acceptability of governmental regulations in the environmental field [32]. There have been few attempts to investigate the role of other emotions such as interest, worry, anger or hope in policy acceptability in this context, but the studies indicate that emotions may be important [33]. Often, the attitudes towards specific policies are grounded in emotional and value-related motives, rather than the more specific expected outcomes of the scheme [20]. In this sense, there is a need to consider the role of specific and general emotions and feelings in policy acceptability [22].

In addition to policy-specific beliefs, trust and emotions, views on the process through which it was decided upon may also affect its acceptability [19,33]. It is assumed that it is not only the legitimacy of political authority itself that influences how the public perceives a political instrument but also the extent to which the implementation of the instrument has been made in accordance with a set of justifiable rules of political decision-making [19]. Both institutional trust and perceived process legitimacy can also influence policy-specific beliefs and emotions.

Following the research reviewed in this section and especially the work by Eliasson and Jonsson [6] and Jagers, Matti and Nilsson [19], our analytical model in this study aims to integrate the various dimensions underlying public acceptance. We suggest that acceptability and acceptance of LEZs are influenced first and foremost by policy-specific beliefs and emotions, institutional trust and perceived process legitimacy. Acceptance is also influenced indirectly by individuals' prior attitudes and orientations, problem perception and personal characteristics. The policy instrument's characteristics and the individual-level factors proposed in the model may combine to influence reactions to 
and acceptance of the policy instrument. Other contextual factors affecting both the level of acceptance per se and the factors and mechanisms determining acceptance, such as personal experience (see status quo bias in $[24,34,35]$ ) or the framing and packaging of the policy instrument $[21,24,36]$, are not considered here.

\section{Materials and Methods}

\subsection{Procedure and Participants}

The study was conducted through a self-administered survey (online) among residents in Barcelona, Spain. Respondents older than 18 years living in the area affected by the LEZ were recruited from an internet panel managed by Dynata to form a quota sample representative of the population of Barcelona. The data were collected in May 2020. The survey drop-out rate was of $5 \%$. The final number of participants in the study was 581 (Table 1). Fixed quotas were used for sex and age and soft quotes for educational level, resulting in a sample with a higher level of education than the general population. Nearly half of the sample was female (47\%) with an average age of 45 years. Most of them hold a university degree $(63 \%)$. Almost half of them reported using a car or bike in their daily lives, and most of the sample reported owning a car.

Table 1. Sample characteristics ${ }^{1 .}$

\begin{tabular}{cc}
\hline Male (\%) & 53 \\
\hline 18-39 years & 39 \\
40-65 years & 48 \\
65+ years & 13 \\
Education level (\% university degree) & 63 \\
Car ownership (\% yes) & 66 \\
Motorbike ownership (\%) & 27 \\
Daily use of car/motorbike (\%) & 50 \\
\hline
\end{tabular}

${ }^{1} \mathrm{~N}=581$.

\subsection{Questionnaire}

The questionnaire was designed based on a review of previous studies $[14,17,19,28]$. In addition to collecting basic demographic information about participants, we included questions dealing with problem perception, institutional trust and prior values and attitudes, such as pro-environmental identity or attitudes towards the use of cars or pedestrianisation. Then, one-page information about the LEZ was provided to participants. The last part of the questionnaire included questions and items measuring familiarity, perceived effectiveness, perception of personal and global impacts, affect, perception of fairness, perceived process legitimacy, overall evaluation of the LEZ and acceptance (see Table 2).

Table 2. Items for studied variables.

\begin{tabular}{ccc}
\hline Variable & Survey Question & Response Categories \\
\hline Problem perception & $\begin{array}{c}\text { In your opinion, the level of air } \\
\text { pollution in Barcelona is . . }\end{array}$ & $\begin{array}{c}\text { 1 (not a problem) to 5 (a very serious } \\
\text { problem) }\end{array}$ \\
Institutional trust & $\begin{array}{c}\text { To what extent do you agree with the } \\
\text { following statement? “The current local } \\
\text { government of Barcelona is capable of } \\
\text { making good decisions regarding the } \\
\text { problem of pollution" }\end{array}$ & 1 (Totally disagree) to 5 (totally agree) \\
Pro-environmental self-identity & $\begin{array}{c}\text { "I consider myself a person very } \\
\text { concerned about } \\
\text { environmental problems" }\end{array}$ & 1 (Totally disagree) to 5 (totally agree) \\
\hline Attitude towards pedestrianization & "The city centre should be pedestrian" & 1 (Totally disagree) to 5 (totally agree) \\
\hline
\end{tabular}


Table 2. Cont.

\begin{tabular}{|c|c|c|}
\hline Variable & Survey Question & Response Categories \\
\hline Attitude towards the use of the car in the city & $\begin{array}{l}\text { "I want to use the car/motorcycle } \\
\text { whenever I want" }\end{array}$ & 1 (Totally disagree) to 5 (totally agree) \\
\hline Being personally affected by LEZ & $\begin{array}{l}\text { Have you been directly affected by this } \\
\text { measure? Have you had to stop using } \\
\text { your car/motorcycle as a result of the } \\
\text { implementation of the LEZ? }\end{array}$ & 1- Yes, 2- No, 3- I don't know \\
\hline Affect & $\begin{array}{l}\text { To what extent does this measure } \\
\text { makes you feel? }\end{array}$ & 1 (Anger) to 5 (Joy) \\
\hline Perceived effectiveness & $\begin{array}{l}\text { "I believe that the Low Emission Zone } \\
\text { will be effective in reducing air } \\
\text { pollution in Barcelona" }\end{array}$ & 1 (Disagree) to 5 (Agree) \\
\hline Personal impacts & $\begin{array}{l}\text { "This measure improves my quality } \\
\text { of life" }\end{array}$ & 1 (Disagree) to 5 (Agree) \\
\hline Global impacts & $\begin{array}{l}\text { "This measure will improve the quality } \\
\text { of life of the citizens" }\end{array}$ & 1 (Disagree) to 5 (Agree) \\
\hline Perceived fairness & $\begin{array}{l}\text { In general, do you think the LEZ is a } \\
\text { fair or unfair measure? }\end{array}$ & 1 (Very unfair) to 5 (Very fair) \\
\hline Process legitimacy & $\begin{array}{l}\text { How democratic and open do you think } \\
\text { the implementation of this measure } \\
\text { has been? }\end{array}$ & $\begin{array}{l}1 \text { (No democratic at all) to } 5 \\
\text { (Very democratic) }\end{array}$ \\
\hline Overall evaluation of LEZ & $\begin{array}{l}\text { In general, do you consider the Low } \\
\text { Emission Zone a measure ...? }\end{array}$ & 0 (Very bad) to 10 (Very good) \\
\hline Acceptance of LEZ in Barcelona & $\begin{array}{c}\text { The definitive application of the Low } \\
\text { Emission Zone in Barcelona seems } \\
\text { to you: }\end{array}$ & $\begin{array}{l}1 \text { (Totally unacceptable) to } 5 \\
\text { (Totally acceptable) }\end{array}$ \\
\hline
\end{tabular}

\subsection{Analysis}

Univariate descriptive analysis of the main dependent variable (acceptance) was carried out using SPSS 23.

Bivariate analysis was conducted to explore initial relations among acceptance of the LEZ and independent variables and to examine the differences between those who support and oppose the LEZ. For this purpose, respondents were categorized as opponents or supporters based on their response to the following question: "The definitive application of the Low Emission Zone in Barcelona seems to you ... ?" (response scale from 1 "Totally unacceptable" to 5 "Totally acceptable"). Those who chose 1 or 2 were considered opponents; those who choose 4 or 5 were considered supporters. Response 3 was considered neutral, and the respondents who chose this answer were excluded from this analysis. Of the 581 respondents, 369 respondents were considered supporters and 100 opponents. The supporters and opponents were compared regarding their personal characteristics, their prior attitudes and their beliefs regarding the implementation of the LEZ measure. Pearson's $\chi 2$ test and an ANOVA test were used to explore the differences in the previous verifications of the normality of the measures between opponents and supporters.

Finally, path analysis modelling was used to examine the net association between the various independent variables included in the model and acceptance. A multivariate regression analysis was run for each of the endogenous variables. Standardized coefficients for direct and indirect effects were calculated for all the possible paths in the model. Only the paths with a significant effect (2-sided bootstrapped $p$-value $<0.05$ ) were kept in the model. Given that the path analysis was based on non-latent variables, the coefficient of determination $\left(R^{2}\right)$ was used as a measure of overall model fit. The data conformed to normality based on the normal probability Q-Q plot of residuals. 


\section{Results}

\subsection{Descriptive and Bivariate Analysis}

Table 3 shows the distribution of acceptance of the LEZ among survey respondents. The results show that most respondents (64\%, CI: $56 \%-70 \%)$ accepted the definitive application of the LEZ in Barcelona, 19\% (CI: 16\%-23\%) were unsure and 17\% (CI: 13\%-22\%) rejected its application.

Table 3. Responses to the definitive application of the Low Emission Zone in Barcelona.

\begin{tabular}{|c|c|c|c|}
\hline & \multirow[b]{2}{*}{$\%$} & \multicolumn{2}{|c|}{ 95\% CI (Bootstrap) } \\
\hline & & Lower & Upper \\
\hline Totally unacceptable & 6 & 4 & 8 \\
\hline Unacceptable & 11 & 9 & 14 \\
\hline Neither acceptable nor unacceptable/undecided & 19 & 16 & 23 \\
\hline Acceptable & 45 & 40 & 48 \\
\hline Totally acceptable & 19 & 16 & 22 \\
\hline Total & $100 \%$ & & \\
\hline
\end{tabular}

Table 4 shows the differences in terms of personal characteristics, prior attitudes, policy beliefs, emotions and trust between those expressing relatively low and high levels of acceptance of the LEZ. Our bivariate analysis showed relevant differences in terms of age (opponents were slightly older on average), political ideology (supporters were more likely to place their political views to the left on the political scale), car ownership ( $80 \%$ of car ownership among opponents versus $62 \%$ among supporters) and being personally affected by LEZ (opponents were more likely to be affected by the measure than supporters). Supporters, on average, were more likely to perceive air pollution in the city as a serious problem than opponents $(76 \%$ vs. $47 \%)$, who were more likely to report a proenvironmental identity ( $83 \%$ vs. $63 \%$ ) and were more in favour of pedestrianisation $(70 \%$ vs. $29 \%$ ). Supporters were also significantly more likely to perceive the implementation of the LEZ as democratic than opponents ( $53 \%$ vs. $0 \%$ ), who reported significantly higher levels of political trust $(43 \% \mathrm{vs.} 7 \%)$, were less likely to report anger regarding the measure $(8 \%$ vs. $73 \%)$ and perceived it as more fair (79\% vs. $3 \%)$ and effective to reduce air pollution in the city ( $77 \%$ vs. $20 \%)$. Supporters were also significantly more likely to perceive that the LEZ has positive personal (improved life quality in the city) (76\% vs. $14 \%)$ and global (improved citizens' health) impacts (88\% vs. $23 \%$ ).

Table 4. Comparison between respondents supporting and opposing LEZ implementation.

\begin{tabular}{|c|c|c|c|}
\hline & Opponents $(n=100)$ & Supporters $(n=369)$ & $p$-Value \\
\hline Female $(\%)$ & $46 \%$ & $45 \%$ & 0.895 \\
\hline Age (mean) & 48.1 & 43.9 & 0.011 \\
\hline Education (\% university studies) & $62 \%$ & $64 \%$ & 0.887 \\
\hline Political ideology (mean) & 3.0 & 2.7 & 0.045 \\
\hline Car ownership (\%) & $80 \%$ & $62 \%$ & 0.001 \\
\hline Car/motorbike use $(\%)$ & $46 \%$ & $52 \%$ & 0.317 \\
\hline Affected by LEZ $(\%)$ & $38 \%$ & $17 \%$ & 0.001 \\
\hline Problem perception (\% serious or very serious problem) & $47 \%$ & $76 \%$ & 0.001 \\
\hline Pro-environmental identity $(\%)$ & $63 \%$ & $83 \%$ & 0.001 \\
\hline Attitude towards pedestrianisation ( $\%$ in favour) & $29 \%$ & $70 \%$ & 0.001 \\
\hline Attitude-freedom to use car (\% in favour) & $71 \%$ & $33 \%$ & 0.001 \\
\hline Perceived effectiveness (\% high and very high) & $20 \%$ & $77 \%$ & 0.001 \\
\hline Personal impacts (improve your quality of life \%) & $14 \%$ & $76 \%$ & 0.001 \\
\hline Global impacts (improve citizens' quality of life \%) & $23 \%$ & $88 \%$ & 0.001 \\
\hline Affect (\% angry) & $73 \%$ & $8 \%$ & 0.001 \\
\hline Perceived process legitimacy ( $\%$ democratic) & $0 \%$ & $53 \%$ & 0.001 \\
\hline Perceived fairness (\% fair or very fair) & $3 \%$ & $79 \%$ & 0.001 \\
\hline Institutional trust (\% of high and very high) & $7 \%$ & $43 \%$ & 0.001 \\
\hline
\end{tabular}




\subsection{What Explains Public Acceptance?}

With the aim of examining the direct and indirect determinants of acceptance of the Barcelona LEZ suggested in our analytical model, a path analysis with a selected number of independent variables was estimated for the whole sample. Figure 3 displays the proposed path diagram. Table 5 shows the direct and indirect standardized effects of the selected explanatory variables (institutional trust, perceived global impacts, affect, perceived process legitimacy, problem perception, environmental self-identity, car ownership and political ideology) over acceptance.

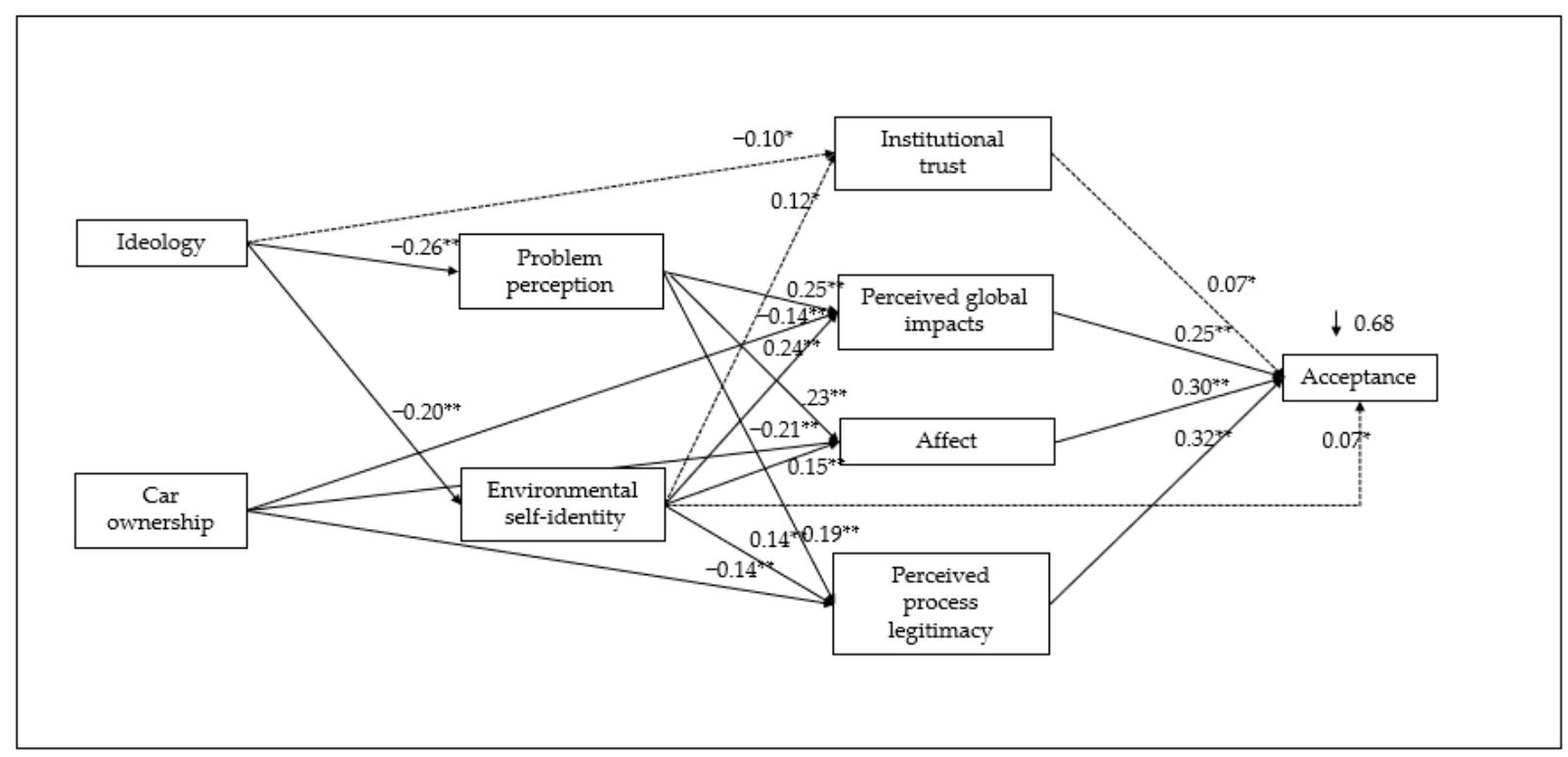

Figure 3. Final path model with standardized regression coefficients ${ }^{* *} 2$-sided bootstrapped $p$-value $<0.01$; ${ }^{*} 2$-sided bootstrapped $p$-value $<0.05)$.

Table 5. Direct and indirect effects of independent variables on LEZ acceptance.

\begin{tabular}{ccc}
\hline & $\begin{array}{c}\text { Direct Effect } \\
\text { Beta Coeff. } \\
(p \text {-Value })\end{array}$ & $\begin{array}{c}\text { Indirect Effect } \\
\text { Beta Coeff. } \\
(p \text {-Value })\end{array}$ \\
\hline $\begin{array}{c}\text { Institutional trust } \\
\text { Perceived global impacts } \\
\text { Affect }\end{array}$ & $0.07(0.02)$ & \\
Perceived process legitimacy & $0.25(0.00)$ & \\
Problem perception & $0.30(0.00)$ & $0.19(0.01)$ \\
Environmental identity & $0.32(0.00)$ & $0.16(0.01)$ \\
Political ideology & - & $0.09(0.01)$ \\
Car ownership & $0.07(0.01)$ & $-0.14(0.01)$ \\
\hline
\end{tabular}

Results from the model show, first, that perceived global impacts affecting perceived process legitimacy and institutional trust were significant direct contributors to the variation in acceptance of the LEZ. Perceived process legitimacy was the strongest predictor of acceptance (direct effect of 0.32 ), followed by affect (direct effect of 0.30 ) and perceived global impacts (direct effect of 0.25 ). Institutional trust had a weak but significant effect on acceptance (direct effect of 0.07).

Second, problem perception influenced acceptance indirectly through perceived global impacts, affect and perceived process legitimacy (indirect effect of 0.19). Environmental self-identity was directly associated with acceptance (a higher pro-environmental identity increased acceptance) and also indirectly through institutional trust, perceived global impacts, affect and perceived process legitimacy (total effect of 0.23 ). The indirect effect of both variables on acceptance was stronger relative to their direct effect. Political ideology 
was indirectly associated with acceptance through institutional trust, problem perception and environmental self-identity (indirect effect of 0.08 ). Car ownership was associated with acceptance through its association with perceived global impacts, affect and perceived process legitimacy (indirect effect of -0.14 )

Overall, the regression model had a good model fit (Adj. $\mathrm{R} 2=0.68, \mathrm{~F}=141.5, p=0.00$ ). Table 5 summarizes the effects of each of the variables in the model on acceptance of the LEZ.

\section{Discussion}

In this paper, we used survey data to examine the relative impact of various individuallevel variables (personal characteristics, prior values and attitudes, problem perception, policy-specific beliefs, perceived process legitimacy and institutional trust) on the public acceptance of an LEZ among residents in Barcelona, Spain. This is the first paper to look specifically at the attitudinal and sociodemographic factors influencing the public acceptance of low-emission zones. The paper also contributes to the literature on public attitudes towards policy interventions to reduce urban air pollution by assessing the relative impact of these factors quantitatively. We offer a framework for comprehensively examining public reactions to these policies, assuming that public acceptance is essential to effective and sustainable implementation. Application of our framework to urban air pollution problems in other countries is straightforward and relevant.

We report on the following main findings. First, we found that most surveyed residents accepted the implementation of the LEZ. They generally perceived that the LEZ was effective in reducing urban air pollution, believed it would have positive personal and global impacts and regarded it as a fair measure. This finding is consistent with previous research on the acceptance of low-emission zones [2] and, more broadly, on the acceptance of measures to restrict access to certain areas of the cities. Improved public transport systems and restricting access are usually the measures with higher levels of public acceptance, relative to congestion charges $[37,38]$. Our data seem to confirm this observation. The Barcelona LEZ is a policy instrument recently introduced in the city that, after four months of partial implementation (as fines were not enforced by the time of the study), has relatively high public support levels.

Second, and in line with previous expectations $[19,22,39]$, the results of the bivariate analysis showed that the acceptance of the LEZ was significantly associated with policyspecific beliefs, affect, perceived process legitimacy and trust and, to a lesser extent, with individuals' prior attitudes, such as the attitude towards the use of a car, problem perception, pro-environmental self-identity or the attitude towards pedestrianisation as well as to sociodemographics, mainly car ownership and political ideology. Clearly, all these factors deserve a place in conceptual models that try to explain the acceptability of environmental policies [22]

Third, using path analysis modelling, we found that for the perceived global impacts of the LEZ, affect and perceived process legitimacy were the most relevant factors explaining differences in acceptance among individuals. Consistent with previous research (e.g., Jagers, Matti and Nilsson [19] found that expected outcomes and perceived fairness were the variables most strongly associated with acceptance, followed by perceived process legitimacy), policy-specific beliefs and perceived process legitimacy played a key role in acceptance. Although not considered extensively in previous research, our data also showed that feelings towards the policy measure had a relevant role in acceptance. As indicated by recent reviews [22], the role of emotions such as interest, worry, anger and hope clearly requires more attention in future research. Interestingly, institutional trust had, according to our data, a very limited explanatory power.

Our model also showed, consistently with previous research $[6,17,20]$, the important role of prior attitudes and orientations in acceptance. Problem perception and environmental self-identity had, according to our path analysis and consistent with our hypothesis, a significant indirect effect on acceptance. The data suggest that prior attitudes influence acceptance mainly indirectly and that this influence is relevant but weaker relative to the influence of beliefs and emotions directly related to the policy under study. Finally, 
personal characteristics had, consistent with our expectations and prior research, a relevant and indirect influence over acceptance. Specifically, car ownership and political ideology significantly influenced acceptance through prior attitudes and policy-specific beliefs and emotions.

The results of the study have some relevant implications for policy. First, emphasizing the positive impacts of the LEZ on the citizens' quality of life may have more positive impacts on acceptance than to highlight their effectiveness to reduce air pollution. Additionally, the more the LEZ is sensitive and avoids generating unfair effects within the general public and particular groups, the more likely the implementation will gain support. The legitimacy of the process of implementation of the low-emission zone as well as the emotions associated with this instrument are also relevant factors in acceptance. In this sense, a positive engagement with residents may contribute to acceptance and support for the LEZ. Finally, prior personal orientations should be considered when engaging and communicating with the residents.

There are several limitations in this study that must be acknowledged. First, this study used a quota sample derived from an online panel that is not representative of the city of Barcelona. We have a slightly skewed sample: our sample includes more educated and young respondents compared to the general population, so the generalizability of the descriptive results remains limited. Second, our empirical research focused on one city and on one policy instrument. We did not consider other policy instruments currently discussed in other countries. Comparing acceptance of LEZs across a range of countries and among other policy interventions could offer further insights. Third, the research was not developed using a specific attitudinal theory. Instead, this study sought to broadly assess predictors of acceptance. In this sense, even though the explained variance in acceptability was reasonably high, there may be additional determinants of acceptance. Furthermore, it is not possible to draw causal conclusions of the order between variables in the examined model. Experimental or longitudinal studies would be needed to establish the specific order of relations.

In this paper, we investigated the individual-level factors explaining the public acceptance of an LEZ. Our findings offer new insights into how citizens form attitudes with respect to policy interventions to reduce urban air pollution. Using the case of the Barcelona low-emission zone and based on a survey among residents, we can conclude that although our cross-sectional design does not allow for causal inferences, policy-specific beliefs, affect and opinions on process legitimacy have a significant direct effect on acceptance. We also note that prior attitudes and personal orientations and, to a lesser extent, personal characteristics, are significantly associated, mainly indirectly, with levels of acceptance.

Author Contributions: Conceptualization, C.O., R.S. and À.B.; methodology, C.O., R.S., S.L.-A. and S.G.; software, C.O., R.S., S.L.-A. and S.G.; formal analysis, C.O., R.S., S.L.-A. and S.G.; writingoriginal draft preparation, C.O. and R.S.; writing-review and editing, C.O., R.S., S.L.-A., and À.B.; project administration, C.O. and R.S.; funding acquisition, C.O. and R.S. All authors have read and agreed to the published version of the manuscript.

Funding: This research was funded by Agencia Estatal de Investigación (Proyectos de I+D+i Retos Investigación), Ministerio de Ciencia, Innovación y Universidades, España.

Data Availability Statement: The data presented in this study are available on request from the corresponding author. The data are not publicly available because the authors were unable to find a valid data repository for the data used in this study.

Conflicts of Interest: The authors declare no conflict of interest.

\section{References}

1. European Commission. A Europe That Protects: Clean Air for All; European Commission: Luxembourg, 2018.

2. Transport \& Environment. City Bans Are Spreading in Europe; Transport \& Environment: Brussels, Belgium, 2018.

3. Dablanc, L.; Montenon, A. Impacts of Environmental Access Restrictions on Freight Delivery Activities Example of Low Emissions Zones in Europe. Transp. Res. Rec. 2015, 2478, 12-18. [CrossRef] 
4. Holman, C.; Harrison, R.; Querol, X. Review of the Efficacy of Low Emission Zones to Improve Urban Air Quality in European Cities. Atmos. Environ. 2015, 111, 161-169. [CrossRef]

5. Allen, S.; Gaunt, M.; Rye, T. An Investigation into the Reasons for the Rejection of Congestion Charging by the Citizens of Edinburgh. Eur. Transp. 2006, 32, 95-113.

6. Eliasson, J.; Jonsson, L. The unexpected "yes": Explanatory factors behind the positive attitudes to congestion charges in Stockholm. Transp. Policy 2011, 18, 636-647. [CrossRef]

7. Schade, J.; Schlag, B. Acceptability of urban transport pricing strategies. Transp. Res. Part F Traffic Psychol. Behav. 2003, 6, 45-61. [CrossRef]

8. Gärling, T. Effectiveness, Public Acceptance, and Political Feasibility of Coercive Measures for Reducing Car Traffic. In Threats from Car Traffic to the Quality of Urban Life; Emerald Publishing Limited: Bingley, UK, 2007; Volume 63, pp. 313-324. [CrossRef]

9. Steg, L.; Schuitema, G. Behavioural Responses to Transport Pricing: A Theoretical Analysis. In Threats from Car Traffic to the Quality of Urban Life; Emerald Publishing Limited: Bingley, UK, 2007; pp. 347-366. [CrossRef]

10. Givoni, M. Addressing transport policy challenges through Policy-Packaging. Transp. Res. Part A Policy Pract. 2014, 60, 1-8. [CrossRef]

11. Wicki, M.L.; Huber, R.A.; Bernauer, T. Can policy-packaging increase public support for costly policies? Insights from a choice experiment on policies against vehicle emissions. J. Public Policy 2020, 40, 599-625. [CrossRef]

12. Jia, N.; Zhang, Y.; He, Z.; Li, G. Commuters' acceptance of and behavior reactions to license plate restriction policy: A case study of Tianjin, China. Transp. Res. Part D Transp. Environ. 2017, 52, 428-440. [CrossRef]

13. Raux, C.; Souche, S. The Acceptability of Urban Road Pricing A Theoretical Analysis Applied to Experience in Lyon. J. Transp. Econ. Policy 2004, 38, 191-215.

14. Beck, M.J.; Rose, J.M.; Hensher, D.A. Environmental attitudes and emissions charging: An example of policy implications for vehicle choice. Transp. Res. Part A Policy Pract. 2013, 50, 171-182. [CrossRef]

15. Zheng, Z.; Liu, Z.; Liu, C.; Shiwakoti, N. Understanding public response to a congestion charge: A random-effects ordered logit approach. Transp. Res. Part A Policy Pract. 2014, 70, 117-134. [CrossRef]

16. Jakobsson, C.; Fujii, S.; Gärling, T. Determinants of private car users' acceptance of road pricing. Transp. Policy 2000, 7, 153-158. [CrossRef]

17. Eriksson, L.; Garvill, J.; Nordlund, A.M. Acceptability of single and combined transport policy measures: The importance of environmental and policy specific beliefs. Transp. Res. Part A Policy Pract. 2008, 42, 1117-1128. [CrossRef]

18. Kallbekken, S.; Sælen, H. Public acceptance for environmental taxes: Self-interest, environmental and distributional concerns. Energy Policy 2011, 39, 2966-2973. [CrossRef]

19. Jagers, S.; Matti, S.; Nilsson, A. How exposure to policy tools transforms the mechanisms behind public acceptability and acceptance-The case of the Gothenburg congestion tax. Int. J. Sustain. Transp. 2017, 11, 109-119. [CrossRef]

20. Nilsson, A.; Schuitema, G.; Bergstad, C.J.; Martinsson, J.; Thorson, M. The road to acceptance: Attitude change before and after the implementation of a congestion tax. J. Environ. Psychol. 2016, 46, 1-9. [CrossRef]

21. Wicki, M.L.; Fesenfeld, L.; Bernauer, T. In search of politically feasible policy-packages for sustainable passenger transport: Insights from choice experiments in China, Germany, and the USA. Environ. Res. Lett. 2019, 14, 084048. [CrossRef]

22. Ejelöv, E.; Nilsson, A. Individual Factors Influencing Acceptability for Environmental Policies: A Review and Research Agenda. Sustainability 2020, 12, 2404. [CrossRef]

23. Drews, S.; Bergh, J.C.V.D. What explains public support for climate policies? A review of empirical and experimental studies. Clim. Policy 2016, 16, 855-876. [CrossRef]

24. Börjesson, M.; Eliasson, J.; Hamilton, C. Why experience changes attitudes to congestion pricing: The case of Gothenburg. Transp. Res. Part A Policy Pract. 2016, 85, 1-16. [CrossRef]

25. Basbas, S.; Kladias, E.; Kouvatas, S.; Politis, I. Investigation of the user's acceptance concerning a Low Emission Zone in the center of Thessaloniki, Greece. Transp. Res. Procedia 2017, 24, 280-287. [CrossRef]

26. Hårsman, B.; Quigley, J.M. Political and public acceptability of congestion pricing: Ideology and self-interest. J. Policy Anal. Manag. 2010, 29, 854-874. [CrossRef]

27. Rienstra, S.; Rietveld, P.; Verhoef, E. The social support for policy measures in passenger transport. Transp. Res. Part D Transp. Environ. 1999, 4, 181-200. [CrossRef]

28. Steg, L.; Vlek, C. The Role of Problem Awareness in Willingness-to-Change Car Use and in Evaluating Relevant Policy Measures. In Traffic and Transport Psychology; Elsevier Science: Amsterdam, The Netherlands, 1997; pp. 465-475.

29. Huber, R.A.; Wicki, M.L.; Bernauer, T. Public support for environmental policy depends on beliefs concerning effectiveness, intrusiveness, and fairness. Environ. Politics 2020, 29, 649-673. [CrossRef]

30. Bernauer, T.; Prakash, A.; Beiser-McGrath, L.F. Do exemptions undermine environmental policy support? An experimental stress test on the odd-even road space rationing policy in India. Regul. Gov. 2020, 14, 481-500. [CrossRef]

31. Eiser, J.R.; Miles, S.; Frewer, L.J. Trust, Perceived Risk, and Attitudes Toward Food Technologies1. J. Appl. Soc. Psychol. 2002, 32, 2423-2433. [CrossRef]

32. Zannakis, M.; Wallin, A.; Johansson, L.-O. Political Trust and Perceptions of the Quality of Institutional Arrangements-How do they influence the public's acceptance of environmental rules. Environ. Policy Gov. 2015, 25, 424-438. [CrossRef] 
33. Esaiasson, P. Will citizens take no for an answer? What government officials can do to enhance decision acceptance. Eur. Political Sci. Rev. 2010, 2, 351-371. [CrossRef]

34. Eliasson, J. The role of attitude structures, direct experience and reframing for the success of congestion pricing. Transp. Res. Part A Policy Pract. 2014, 67, 81-95. [CrossRef]

35. Schade, J.; Baum, M. Reactance or acceptance? Reactions towards the introduction of road pricing. Transp. Res. Part A Policy Pract. 2007, 41, 41-48. [CrossRef]

36. Bergquist, P.; Mildenberger, M.; Stokes, L.C. Combining climate, economic, and social policy builds public support for climate action in the US. Environ. Res. Lett. 2020, 15, 054019. [CrossRef]

37. Bartley, B. Mobility Impacts, Reactions and Opinions: Traffic Demand Management Options in Europe: The MIRO Project. Traffic Eng. Control 1995, 36, 596-602.

38. Schlag, B.; Schade, J. Public Acceptability of Traffic Demand Management in Europe. Traffic Eng. Control 2000, 41, 314-318.

39. Sun, X.; Feng, S.; Lu, J. Psychological factors influencing the public acceptability of congestion pricing in China. Transp. Res. Part F Traffic Psychol. Behav. 2016, 41, 104-112. [CrossRef] 